\title{
The Characteristics of False Respondents on Original The Characteristics of False Respondents on Article a Self-reported Smoking Survey of Korean Women: Korean National Health and Nutrition Examination Survey, 2008
}

\author{
Dong Ryul Lee, Hyo-Sung Kim, Jungun Lee*
}

Department of Family Medicine, Wonkwang University Sanbon Hospital, Wonkwang University School of Medicine, Gunpo, Korea

Background: Previous studies have shown that self-reports tend to underestimate smoking status, especially among women in Korea. We therefore assessed the characteristics of Korean women smokers who falsely described themselves as non-smokers.

Methods: The subjects were 4,135 adult women aged $\geq 19$ years who participated in the 2008 Korean National Health and Nutrition Examination Survey. Of these, 3,151 subjects answered questions about their smoking status on self-reported questionnaires and underwent assays of urinary cotinine concentration. Subgroups of false respondents $(\mathrm{n}=131)$ and true respondents $(\mathrm{n}=198)$ regarding smoking were determined by comparing their responses on questionnaires with their urinary cotinine levels.

Results: Among adult Korean women, the self-reported smoking rate was 7.4\% (95\% confidence interval [CI], $6.4 \%$ to $8.4 \%$ ); however, using urinary cotinine $>100 \mathrm{ng} / \mathrm{mL}$ as a marker of smoking, the smoking rate was $11.8 \%$ (95\% CI, $10.5 \%$ to $13.3 \%)$. In multivariate analysis, after adjusting for type of household, family income, and suicidal ideation, the odds ratios (ORs) of false respondents were 3.49 (95\% CI, 1.41 to 8.63) for college-educated women and 2.47 (95\% CI, 1.22 to 5.01) for women with high school education, relative to women with elementary school education. Married women with living spouses (OR, 2.80; 95\% CI, 1.33 to 5.90) were more likely to respond falsely than unmarried women. Women who reported trying to reduce weight within 1 year (OR, 2.70; 95\% CI, 1.47 to 4.93) and those who reported being less stressed (OR, 1.82; 95\% CI, 1.08 to 3.07) were more likely to be false respondents.

Conclusion: The smoking rate determined using urinary cotinine concentration was higher than the self-reported rate among Korean women. Among smokers, those who were more educated, married, living with a husband, trying to reduce weight, and less stressed tended to describe themselves falsely as non-smokers.

Keywords: Korea; Women; Smoking; Smoking Rate; Cotinine

Received: August 31, 2011, Accepted: May 2, 2013

${ }^{*}$ Corresponding Author: Jungun Lee

Tel: +82-31-390-2416, Fax: +82-31-390-2588

E-mail: tracheo@naver.com

Korean Journal of Family Medicine

Copyright (C) 2014 The Korean Academy of Family Medicine

(c) This is an open-access article distributed under the terms of the Creative Commons Attribution Non-Commercial License (http://creativecommons.org/licenses/by-nc/3.0) which permits unrestricted noncommercial use, distribution, and reproduction in any medium, provided the original work is properly cited.

\section{INTRODUCTION}

Smoking is an important public health issue for women, since it affects the development and health of the fetus during pregnancy $^{1-3)}$ and increases the risk of lung, stomach, cervical, bladder, oral, and laryngeal cancer. ${ }^{4)}$ The Korean Institute for Health and Social Affairs reported that the percentage of Korean women smokers increased from $5.1 \%$ in 1992 to $7.4 \%$ in $2008 .^{5)}$

Reducing the smoking rate of adult women requires appro- 
priate policies for smoking cessation. As an initial step, it is necessary to more precisely analyze smoking prevalence in this population. However, previous studies likely underestimated the real smoking rate of Korean women, since the results were usually obtained by administering questionnaires. ${ }^{6)}$ Since Korean society frowns on women smoking, many women smokers conceal this on questionnaires. ${ }^{7,8)}$ Additional research is therefore required to assess women smokers who pretend not to smoke, thereby obtaining more accurate information on smoking rate and behaviors.

Biochemical markers can provide objective information on smoking status. Cotinine, a metabolite of nicotine, is a frequently utilized marker of smoking status, due to its long half-life (range, 18 to 20 hours). Moreover, measurements of urinary cotinine are non-invasive, and cotinine concentrations are not affected by urine $\mathrm{pH}^{9-11)}$

Utilizing the data from the Korean National Health and Nutrition Survey in 2008, we analyzed the demographic, physical, and psychological characteristics of Korean women smokers, as determined by urinary cotinine concentrations, who self-report as being non-smokers.

\section{METHODS}

\section{Subjects}

This study consisted of 4,135 adult women, aged $\geq 19$ years, who participated in the Korean National Health and Nutrition Survey in 2008. Of these, 3,151 subjects answered questions about their smoking status on self-reported questionnaires and underwent assays of urinary cotinine concentration. Although urinary cotinine concentration ranged from 20 to $500 \mathrm{ng} / \mathrm{mL}$, the cut-off level distinguishing smokers from nonsmokers was normally not higher than $100 \mathrm{ng} / \mathrm{mL} .{ }^{11,12)}$ To avoid including secondhand-smokers, we considered subjects with urinary cotinine levels higher than $100 \mathrm{ng} / \mathrm{mL}$ as 'biochemically determined smokers.'

\section{Definitions of Smokers and False Respondents \\ Smokers were defined as those who answered 'yes' to the question, "do you smoke?" or had a urinary cotinine level $>100$ $\mathrm{ng} / \mathrm{mL}(\mathrm{n}=328)$. Nonsmokers were defined as those who}

answered 'no' to the question about smoking or had a urinary cotinine level $<100 \mathrm{ng} / \mathrm{mL}(\mathrm{n}=2,823)$. A false respondent was defined as a person who answered 'no' to the question about smoking but had a urinary cotinine concentration $>100 \mathrm{ng} / \mathrm{mL}$ ( $\mathrm{n}=131)$, and a true respondent was defined as a person who answered 'yes' to the question about smoking, regardless of the results of urinary cotinine tests $(n=198)$.

\section{Measurement of Variables}

All questionnaires were administered to subjects in their homes by direct interviews with interviewers who had completed the required training. Social and economic variables considered included subject age (19-29, 30-39, 40-49, 50-59, or > 60 years), area of residence (eup/myeon [rural] or dong [urban]), level of education (graduation from elementary, middle, or high school or from college/university), marital status, occupational status (employed or not, with the latter including housewives), and type of occupation (non-manual jobs [e.g., managers, consultants or related jobs, and office workers] or manual jobs [service or sales jobs, skilled workers or technicians in the agricultural and fishing industries, employees of device/machine manufacturers, or jobs requiring simple physical work]). Other factors included type of household (one person, one generation [a married couple or the respondent and unmarried siblings or relative], two generations [a married couple or the respondent plus children or parents], and three generations [a married couple or the respondent plus both children and parents]), and household income (upper, uppermiddle, middle class, or lower class). Psychological and physical characteristics included subjective determinations of health (using the question "do you think you are healthy enough?"), body shape (normal, too thin, or too heavy), stress, depression (for $>2$ weeks), and suicidal ideation (within the previous year). Lifestyle variables included monthly frequency of alcohol consumption, moderate or vigorous physical activity (more than 20 minutes per session and more than 3 times per week), walking, and attempts to control weight (increase, decrease, or maintain) during the previous year. We also analyzed whether a subject was exposed to secondhand smoke at home, and length of exposure (none, $<1$ hour, or $>1$ hour), in order to evaluate the effects of secondhand smoke on urinary cotinine concentrations. 


\section{Measurement of Urine Cotinine}

Until February 15, 2008, urinary cotinine levels were measured at Seoul Medical Science Institute using a tandem mass spectrometer (API 4000; Applied Biosystems, Foster City, CA, USA) and cotinine reagent (Sigma, St. Louis, MO, USA). After February 20, 2008, urinary cotinine was measured at Neodin Medical Institute using a gas chromatograph (Clarus 600T; PerkinElmer, Turku, Finland), and cotinine reagent (Sigma).

\section{Statistics}

Due to the multistage probability sampling design of the National Health and Nutrition Survey of 2008, all analyses incorporated sampling weight. The Rao-Scott chi-square test was used to analyze differences between the general characteristics of smokers and nonsmokers, whereas multiple logistic regression analysis was used to compare the characteristics of false and true respondents, including calculations of odds ratios (ORs) and $95 \%$ confidence intervals (CIs). All statistical analyses were performed with SPSS ver. 16.0 (SPSS Inc., Chicago, IL, USA) for MS Windows. A P-value $<0.05$ was considered statistically significant.

\section{RESULTS}

\section{Smoking Rate}

Of the 3,151 subjects, 328 (10.4\%) had urinary cotinine levels above $100 \mathrm{ng} / \mathrm{mL}$. Using weighted analysis, the smoking rate based on urinary cotinine concentrations was $11.8 \%$ (95\% CI, $10.5 \%$ to $13.3 \%)$. In contrast, only 198 out of the 3,151 respondents $(6.3 \%)$ referred to themselves as smokers, with the weight self-reported smoking rate being $7.4 \%$ (95\% CI, $6.4 \%$ to $8.4 \%)$.

\section{General Characteristics of Smokers and Nonsmokers}

The mean urine cotinine concentration was significantly higher in smokers than in non-smokers $(788.4 \mathrm{ng} / \mathrm{mL}$ vs. 11.7 $\mathrm{ng} / \mathrm{mL}, \mathrm{P}<0.001)$. The average age of smokers was 41.8 years, which was lower than that of nonsmokers ( 46.8 years old). There were more smokers in younger age groups (19-29 and 30-39 years) and more nonsmokers in middle aged groups ( $>40$ years)
$(\mathrm{P}<0.001)$. A significantly higher percentage of more educated (high school or higher) than of less educated (middle school or lower) women were smokers $(\mathrm{P}<0.001)$. Single, divorced, widowed and separated women were significantly more likely to be smokers than were women living with spouses $(\mathrm{P}<0.001)$. Women who drank more than one glass of alcohol per month were significantly more likely to be smokers $(\mathrm{P}<0.001)$, as were women who felt depressed $(\mathrm{P}<0.001)$, stressed $(\mathrm{P}=0.007)$, or had suicidal ideations $(\mathrm{P}<0.001)$.

\section{Characteristics of True and False Respondents}

Univariate analysis showed differences between false and true respondents with regard to educational level, marital status, household income, household composition, weight control, amount of stress, and suicidal ideation (Tables 1, 2). Higher educational levels were associated with an increased frequency of false reports. Relative to women who had graduated from elementary school, those who graduated from high school (OR, 2.87 ; $95 \% \mathrm{CI}, 1.43$ to 5.78 ) or college (OR, 3.15; $95 \% \mathrm{CI}, 1.63$ to 6.08 ) were more likely to be false respondents. Relative to single women, those who were divorced or widowed or separated (OR, 1.08 ; $95 \% \mathrm{CI}, 0.48$ to 2.44 ), and those who were married and living with spouses (OR, 2.44; 95\% CI, 1.24 to 4.81) were more likely to report falsely. False responses were more likely in women with higher than lower household income (OR, 2.50; 95\% CI, 1.11 to 5.64); and those living in 2- (OR, 2.85; 95\% CI, 1.17 to 6.96) or 3- or more (OR, 2.82; 95\% CI, 1.09 to 7.26) generation households than in women living alone. Women trying to maintain (OR, 2.45; 95\% CI, 1.07 to 5.62) or lose (OR, 2.64; $95 \% \mathrm{CI}, 1.62$ to 4.30 ) weight during the previous year were more likely to report falsely than women not trying to control their weight. False reports were more frequent in non-stressed than in stressed women (OR, 1.65; 95\% CI, 1.06 to 2.56) and in women who did not have than did have suicidal ideation (OR, 2.11; $95 \%$ CI, 1.29 to 3.47 ).

Multivariate analysis, using multiple logistic regression, showed that after adjusting for household income and composition and suicidal ideation, educational level, marital status, efforts to control weight, and stress remained significant independent predictors of false responses (Table 3). Multiple logistic regression analysis also showed that graduation from high school (OR, 2.47; 95\% CI, 1.22 to 5.01) and college or 
Table 1. Demographic characteristics of false and true respondents among women smokers in Korea

\begin{tabular}{|c|c|c|c|c|}
\hline \multicolumn{2}{|r|}{ Characteristic } & \multirow{2}{*}{$\begin{array}{c}\text { True respondents* }(\mathrm{n}=131) \\
46(33.2 \pm 4.6)\end{array}$} & \multirow{2}{*}{$\begin{array}{c}\text { False respondents }^{\dagger}(\mathrm{n}=198) \\
27(28.1 \pm 4.3)\end{array}$} & \multirow{2}{*}{$\begin{array}{c}\text { OR }(95 \% \mathrm{CI}) \\
1.00\end{array}$} \\
\hline Age (y) & $19-29$ & & & \\
\hline & $30-39$ & $37(20.6 \pm 2.7)$ & $35(25.8 \pm 4.2)$ & $1.48(0.71-3.11)$ \\
\hline & $40-49$ & $34(17.3 \pm 3.1)$ & $23(21.4 \pm 3.6)$ & $1.46(0.70-3.08)$ \\
\hline & $50-59$ & $21(8.7 \pm 2.0)$ & $16(11.9 \pm 2.9)$ & $1.61(0.59-4.40)$ \\
\hline & $\geq 60$ & $60(20.2 \pm 3.3)$ & $30(12.9 \pm 3.4)$ & $0.76(0.36-1.58)$ \\
\hline \multirow[t]{2}{*}{ Town } & Urban & $161(88.1 \pm 3.9)$ & $98(85.2 \pm 5.1)$ & 1.00 \\
\hline & Rural & $37(11.9 \pm 3.9)$ & $33(14.8 \pm 5.1)$ & $1.29(0.71-2.33)$ \\
\hline \multirow[t]{4}{*}{ Education } & $\leq$ Elementary & $77(30.5 \pm 3.7)$ & $31(13.5 \pm 3.3)$ & 1.00 \\
\hline & $\leq$ Middle & $14(6.6 \pm 1.7)$ & $8(5.0 \pm 1.4)$ & $1.73(0.93-3.23)$ \\
\hline & $\leq$ High & $83(49.0 \pm 5.0)$ & $68(62.1 \pm 4.1)$ & $2.87(1.43-5.78)$ \\
\hline & $\geq$ College & $24(13.9 \pm 3.7)$ & $23(19.4 \pm 3.0)$ & $3.15(1.63-6.08)$ \\
\hline \multirow[t]{3}{*}{ Marital status } & Unmarried & $44(30.5 \pm 4.4)$ & $18(18.4 \pm 3.3)$ & 1.00 \\
\hline & Married, living alone $e^{\ddagger}$ & $62(25.1 \pm 3.7)$ & $28(16.3 \pm 3.2)$ & $1.08(0.48-2.44)$ \\
\hline & Married, living with husband & $91(44.3 \pm 4.2)$ & $85(65.3 \pm 4.2)$ & $2.44(1.24-4.81)$ \\
\hline \multirow[t]{2}{*}{ Occupation } & Employed & $97(49.3 \pm 3.8)$ & $66(50.6 \pm 5.7)$ & 1.00 \\
\hline & Unemployed & $100(50.7 \pm 3.8)$ & $64(49.4 \pm 5.7)$ & $0.95(0.58-1.53)$ \\
\hline \multirow[t]{3}{*}{ Type of occupation } & Unemployed & $100(50.7 \pm 3.8)$ & $64(49.4 \pm 5.7)$ & 1.00 \\
\hline & Non-manual & $27(16.8 \pm 2.7)$ & $18(14.9 \pm 3.0)$ & $0.91(0.49-1.69)$ \\
\hline & Manual & $70(32.5 \pm 3.3)$ & $48(35.7 \pm 4.6)$ & $1.13(0.66-1.93)$ \\
\hline \multirow[t]{4}{*}{ Household type $\mathrm{s}^{\S}$} & Single person & $34(13.2 \pm 3.2)$ & $13(6.1 \pm 1.8)$ & 1.00 \\
\hline & 1 generation & $42(24.4 \pm 4.9)$ & $19(11.0 \pm 2.5)$ & $0.96(0.37-2.52)$ \\
\hline & 2 generations & $92(48.3 \pm 5.0)$ & $76(64.3 \pm 5.8)$ & $2.85(1.17-6.96)$ \\
\hline & 3 generations & $30(14.1 \pm 2.7)$ & $23(18.5 \pm 5.3)$ & $2.82(1.09-7.26)$ \\
\hline \multirow[t]{4}{*}{ Household income } & Low & $51(20.4 \pm 3.9)$ & $30(15.0 \pm 3.2)$ & 1.00 \\
\hline & Average & $61(35.2 \pm 4.0)$ & $38(29.5 \pm 3.7)$ & $1.15(0.57-2.30)$ \\
\hline & Above average & $42(25.4 \pm 3.6)$ & $26(20.5 \pm 4.4)$ & $1.10(0.47-2.54)$ \\
\hline & High & $35(19.0 \pm 3.1)$ & $35(34.9 \pm 6.6)$ & $2.50(1.11-5.64)$ \\
\hline
\end{tabular}

Analyzed by logistic regression analysis. Values are presented as unweighted numbers (weighted percentage \pm SE).

OR: odds ratios, CI: confidence interval.

*Individuals who responded accurately to the self-reported smoking survey. ${ }^{\dagger}$ Self-reported non-smokers with urinary cotinine $>100 \mathrm{ng} / \mathrm{mL}$. ${ }^{\ddagger}$ Divorced, widowed or separated. ${ }^{\S}$ Single-person household.

higher (OR, 3.49; 95\% CI, 1.41 to 8.63), being married and living with a spouse (OR, 2.80; 95\% CI, 1.33 to 5.90), attempting to lose weight (OR, 2.70; 95\% CI, 1.47 to 4.93 ) and a lower level of stress (OR, 1.82; 95\% CI, 1.08 to 3.07 ) remained significant independent predictors of false responses.

\section{DISCUSSION}

The present study, using data from the Korean National Health and Nutrition Survey of 2008, found that the self-reported smoking rate of Korean women was $7.4 \%$, whereas the rate based on urinary cotinine concentration $>100 \mathrm{ng} / \mathrm{mL}$ was $11.8 \%$ (95\% CI, $10.5 \%$ to $13.3 \%)$. Among smokers, those who were more 
Table 2. Psychological and lifestyle characteristics of false and true respondents among Korean women smokers

\begin{tabular}{|c|c|c|c|c|}
\hline \multicolumn{2}{|c|}{ Characteristic } & \multirow{2}{*}{$\begin{array}{c}\text { True respondents* }(\mathrm{n}=131) \\
62(28.8 \pm 4.0)\end{array}$} & \multirow{2}{*}{$\begin{array}{c}\text { False respondents }{ }^{\dagger}(\mathrm{n}=198) \\
47(41.2 \pm 5.0)\end{array}$} & \multirow{2}{*}{$\frac{\mathrm{OR}(95 \% \mathrm{CI})}{1.00}$} \\
\hline Subjective health status & Good & & & \\
\hline & Adequate & $65(34.7 \pm 4.7)$ & $43(32.6 \pm 4.6)$ & $0.66(0.33-1.32)$ \\
\hline & Poor & $71(36.5 \pm 3.4)$ & $41(26.2 \pm 3.8)$ & $0.50(0.28-0.88)$ \\
\hline \multirow[t]{3}{*}{ Subjective body image } & Normal & $76(38.9 \pm 5.0)$ & $36(31.0 \pm 3.8)$ & 1.00 \\
\hline & Underweight & $47(20.9 \pm 2.7)$ & $21(13.5 \pm 2.4)$ & $0.83(0.51-1.34)$ \\
\hline & Obese & $75(39.3 \pm 5.5)$ & $73(55.4 \pm 5.0)$ & $1.81(0.97-3.39)$ \\
\hline \multirow[t]{4}{*}{ Trying to control weight } & None & $108(47.7 \pm 3.7)$ & $44(26.7 \pm 4.6)$ & 1.00 \\
\hline & Trying to gain weight & $6(3.7 \pm 1.6)$ & $5(2.8 \pm 1.7)$ & $1.39(0.31-6.17)$ \\
\hline & Trying to maintain weight & $17(11.5 \pm 2.9)$ & $15(15.7 \pm 4.2)$ & $2.45(1.07-5.62)$ \\
\hline & Trying to lose weight & $67(37.2 \pm 3.7)$ & $65(54.8 \pm 4.5)$ & $2.64(1.62-4.30)$ \\
\hline \multirow[t]{2}{*}{ Alcohol } & $<14 \mathrm{~g} / \mathrm{mo}$ & $74(31.9 \pm 3.3)$ & $59(36.0 \pm 5.2)$ & 1.00 \\
\hline & $\geq 14 \mathrm{~g} / \mathrm{mo}$ & $124(68.1 \pm 3.3)$ & $71(64.0 \pm 5.2)$ & $0.83(0.48-1.45)$ \\
\hline \multirow[t]{2}{*}{ Stress } & Stressful & $99(53.1 \pm 4.3)$ & $48(40.7 \pm 5.5)$ & 1.00 \\
\hline & Non-stressful & $99(46.9 \pm 4.3)$ & $80(59.3 \pm 5.5)$ & $1.65(1.06-2.56)$ \\
\hline \multirow[t]{2}{*}{ Depression } & Depressive & $54(27.5 \pm 4.4)$ & $31(22.8 \pm 3.7)$ & 1.00 \\
\hline & Non-depressive & $144(72.5 \pm 4.4)$ & $97(77.2 \pm 3.7)$ & $1.29(0.79-2.10)$ \\
\hline \multirow[t]{2}{*}{ Suicidal ideation } & Have been & $79(39.6 \pm 4.5)$ & $34(23.7 \pm 4.6)$ & 1.00 \\
\hline & Never & $117(60.4 \pm 4.5)$ & $94(76.3 \pm 4.6)$ & $2.11(1.29-3.47)$ \\
\hline \multirow[t]{3}{*}{ Passive smoking at home } & Never & $114(54.4 \pm 3.7)$ & $75(56.4 \pm 4.7)$ & 1.00 \\
\hline & $<1 \mathrm{~h}$ & $57(30.7 \pm 3.2)$ & $32(23.5 \pm 3.2)$ & $0.74(0.49-1.10)$ \\
\hline & $\geq 1 \mathrm{~h}$ & $24(14.9 \pm 2.9)$ & $22(20.1 \pm 4.5)$ & $1.30(0.61-2.74)$ \\
\hline \multirow[t]{2}{*}{ Vigorous physical activity } & Yes & $26(13.5 \pm 3.5)$ & $25(21.5 \pm 3.8)$ & 1.00 \\
\hline & No & $171(86.5 \pm 3.5)$ & $103(78.5 \pm 3.8)$ & $0.57(0.28-1.18)$ \\
\hline \multirow[t]{2}{*}{ Moderate physical activity } & Yes & $23(9.1 \pm 2.0)$ & $20(15.0 \pm 3.5)$ & 1.00 \\
\hline & No & $174(90.9 \pm 2.0)$ & $108(85 \pm 3.5)$ & $0.57(0.28-1.16)$ \\
\hline \multirow[t]{2}{*}{ Walking } & Yes & $87(43.6 \pm 3.4)$ & $52(41.5 \pm 5.5)$ & 1.00 \\
\hline & No & $108(56.4 \pm 3.4)$ & $75(58.5 \pm 5.5)$ & $1.09(0.63-1.87)$ \\
\hline
\end{tabular}

Analyzed by logistic regression analysis. Values are presented as unweighted numbers (weighted percentage \pm SE).

OR: odds ratio, CI: confidence interval.

*Individuals who responded accurately to the self-reported smoking survey. ${ }^{\dagger}$ Self-reported non-smokers with urinary cotinine $>100 \mathrm{ng} / \mathrm{mL}$.

educated, married and living with spouses, trying to lose weight, and having less stress tried to conceal their smoking habits.

Previous studies have reported that a higher level of education was associated with lower smoking rates. ${ }^{13,14)}$ However, we found that women with a higher level of education were more likely to conceal their smoking status. Due to the negative image of smoking, women with higher levels of education may have a higher level of self-monitoring and therefore would try to conceal their smoking status.

A previous study from Korea reported a lower smoking rate among women who were married and living with spouses than among unmarried, divorced, widowed or separated women. ${ }^{15)}$ We found, however, that women in the former group were more likely to attempt to hide their smoking from husbands, probably 
Table 3. Multivariate analysis of factors associated with false responses on self-reported smoking survey

\begin{tabular}{llc}
\hline & Variable & OR (95\% CI) \\
\hline Education & $\leq$ Elementary & 1.00 \\
& $\leq$ Middle & $1.36(0.54-3.40)$ \\
& $\leq$ High & $2.47(1.22-5.01)$ \\
& $\geq$ College & $3.49(1.41-8.63)$ \\
Marital status & Unmarried & 1.00 \\
& Married, living alone* & $1.37(0.63-2.99)$ \\
Trying to control & No effort & $2.80(1.33-5.90)$ \\
Weight & Trying to gain weight & $1.43(0.31-6.52)$ \\
& Trying to maintain weight & $2.10(0.91-4.87)$ \\
& Trying to lose weight & $2.70(1.47-4.93)$ \\
Stress & Stressful & 1.00 \\
& Non-stressful & $1.82(1.08-3.07)$ \\
\hline
\end{tabular}

Analyzed by multiple logistic regression analysis. Adjusted for income of the home, household and suicidal ideation.

OR: odds ratio, CI: confidence interval.

*Divorced, widowed, or separated.

because they tended to think that smoking was not good for their health.

We also found that women trying to lose weight tended to provide false reports about smoking status. This may be due to recognition that smoking helps in reducing weight and that stopping smoking could cause weight gain. Although studies from the United States have reported that more nonsmokers than smokers are overweight, ${ }^{16)}$ those studies did not adjust for other variables, including calorie intake, physical activity and socioeconomic status. The relationship between weight loss and smoking is still unclear. Our finding, those women smokers attempting to lose weight tended to conceal their smoking habits, indicates that women who become interested in body shape are likely to be self-conscious about the negative perception of women smoking in Korean society.

Studies investigating the relationship between stress and smoking have reported that stress is an important motivation for smoking. ${ }^{2)}$ We found, however, that women who were less stressed were more likely to falsely report they were nonsmokers. Smokers with a greater level of stress may lack the time and energy required to conceal their smoking habits. In contrast, those who are less stressed may care more about what other people think of them and may tend to conceal that they are smokers.

A literature review of smoking among women found that smoking rates were higher among women of lower rather than higher socioeconomic status. We found, however, that false reports on smoking status were more common among middle and upper class women, those with higher levels of education, those living with their husbands, those trying to control their weight, and those not subjected to much stress. These differences may be due, at least in part, to Korean culture, in which women who smoke are regarded more negatively than men who smoke. Since women with higher levels of self-monitoring may try to conceal their smoking habits, more accurate investigations of smoking in Korean women should not utilize the results of selfreporting surveys only. Rather, these surveys should be adjusted to account for these groups of women who tend to conceal their smoking habits.

This study had several limitations. Due to its cross sectional design, the study could not delineate causal relationships among factors. Second, we used only one measurement, urinary cotinine concentration, to identify false respondents.

Despite these limitations, to our knowledge this study is the first to describe the characteristics of Korean adult women who respond falsely on surveys of smoking status in a nationwide representative population. We also analyzed the socio-economic and psycho-physical characteristics of the false respondents. Accurate assessment of smoking prevalence among Korean women and a determination of the characteristics of women smokers are needed to implement effective policies that reduce smoking rate.

\section{CONFLICT OF INTEREST}

No potential conflict of interest relevant to this article was reported.

\section{REFERENCES}

1. Perkins KA. Smoking cessation in women: special considerations. 
CNS Drugs 2001;15:391-411.

2. Fielding JE. Smoking: health effects and control (1). N Engl J Med 1985;313:491-8.

3. Amos A. Women and smoking. Br Med Bull 1996;52:74-89.

4. Tulloch H, Quinlan B, Jo E, Oc M. Women and smoking cessation. Smok Cessat Rounds 2007;1:1-5.

5. Seo MK. Women's smoking behavior and its implications. Health Policy Forum 2009; (152):73-82.

6. Hwang SJ, Ou SW, Kim SN, Hwang HS, Cho BL, Huh BY. Smoking patterns and factors associated with smoking in Korean adult women. J Korean Acad Fam Med 2000;21:34456.

7. Lee CY, Shin S, Lee HK, Hong YM. Validation of self-report on smoking among university students in Korea. Am J Health Behav 2009;33:540-9.

8. Connor Gorber S, Schofield-Hurwitz S, Hardt J, Levasseur G, Tremblay M. The accuracy of self-reported smoking: a systematic review of the relationship between self-reported and cotinine-assessed smoking status. Nicotine Tob Res 2009;11:12-24.

9. Lerman C, Orleans CT, Engstrom PF. Biological markers in smoking cessation treatment. Semin Oncol 1993;20:359-67.
10. Jarvis MJ, Tunstall-Pedoe H, Feyerabend C, Vesey C, Saloojee Y. Comparison of tests used to distinguish smokers from nonsmokers. Am J Public Health 1987;77:1435-8.

11. Kang YH, Lee YJ, Kim HK, Yun YH, Jeong SY, Lee JS, et al. Usefulness of urinary cotinine test to distinguish smokers from nonsmokers. Korean J Lab Med 2003;23:92-7.

12. Haufroid V, Lison D. Urinary cotinine as a tobacco-smoke exposure index: a minireview. Int Arch Occup Environ Health 1998;71:162-8.

13. Huisman M, Kunst AE, Mackenbach JP. Inequalities in the prevalence of smoking in the European Union: comparing education and income. Prev Med 2005;40:756-64.

14. Cavelaars AE, Kunst AE, Geurts JJ, Crialesi R, Grotvedt L, Helmert U, et al. Educational differences in smoking: international comparison. BMJ 2000;320:1102-7.

15. Cho HJ, Khang YH, Jun HJ, Kawachi I. Marital status and smoking in Korea: the influence of gender and age. Soc Sci Med 2008;66:609-19.

16. Albanes D, Jones DY, Micozzi MS, Mattson ME. Associations between smoking and body weight in the US population: analysis of NHANES II. Am J Public Health 1987;77:439-44. 